\title{
ANALYSIS OF THE EFFECTIVENESS OF COUNSELING AND DIGITAL BOOKLET BY PHARMACIST ON ADHERENCE AND PAIN CONTROL OF CANCER PATIENTS AT DHARMAIS CANCER HOSPITAL
}

\author{
RURYNTA FERLY SHAVIRA ${ }^{1 *}$, RETNOSARI ANDRAJATI ${ }^{1}$, RISANI ANDALASIA PUTRI ${ }^{2}$ \\ ${ }^{1}$ Department of Pharmaceutical Science, Faculty of Pharmacy, University of Indonesia, Depok, West Java, Indonesia. ${ }^{2}$ Department of \\ Pharmacy, Dharmais Cancer Hospital, West Jakarta, Jakarta, Indonesia. Email: rurynta.ferly@ui.ac.id
}

Received: 24 May 2021, Revised and Accepted: 02 August 2021

\begin{abstract}
Objective: This study aimed to compare the effectiveness of counseling and digital booklet on the level of treatment adherence through reduced pain scale, Morisky Medication Adherence Scale (MMAS-8) scores, and pill count scores in patients with cancer pain using opioid analgesics.

Methods: The author conducted this study at Dharmais Cancer Hospital with a quasi-experimental design. The study sample consisted of 134 respondents who met the inclusion and exclusion criteria, underwent a counseling intervention, and received a digital booklet. The author divided the sample into two groups, the counseling group $(n=67)$ and the digital booklet group $(n=67)$. Adherence level was measured using MMAS-8 and pill count. The pain scale was measured using the Numerical Rating Scale. Those measurements were conducted before the intervention (pre-test) and after 2 weeks of provisioning counseling and receipt of the digital booklet (post-test).
\end{abstract}

Results: The results showed that each counseling and digital booklet improve adherence $(\mathrm{p}<0.05)$ and decrease pain scale $(\mathrm{p}<0.05)$. There was a significant difference in changes in the level of adherence $(p=0.027)$ between the two groups. However, there was no significant difference in changes in the pain scale $(\mathrm{p}=0.132)$ between the two groups.

Conclusions: The analysis showed a significant difference $(\mathrm{p}<0.05)$ between adherence level and pain scale before and after intervention by both counseling and digital booklet. Nevertheless, adherent increasing and pain scale reduction by counseling is better than a digital booklet.

Keywords: Adherence, Cancer pain, Counseling, Digital booklet, Pharmacist.

(c) 2021 The Authors. Published by Innovare Academic Sciences Pvt Ltd. This is an open access article under the CC BY license (http://creativecommons.org/ licenses/by/4.0/) DOI: http://dx.doi.org/10.22159/ajpcr.2021v14i8.42167. Journal homepage: https://innovareacademics.in/journals/index.php/ajpcr

\section{INTRODUCTION}

Cancer is one of the leading causes of death worldwide. Global Cancer Observatory data states that in 2020 there were 19.2 million new cases with a death rate of 9.9 million deaths [1]. In 2016, 17.2 million cases of disabilities globally were caused by cancer [2]. One of the factors that cause disability in cancer patients is pain [3]. Pain is also a widespread cause of patient disability in various types of cancer and affects the quality of life of cancer patients [4]. Uncontrolled pain can significantly reduce bodily functions, appetite, sleep, mood, and quality of life [5]

As many as, $66 \%$ of patients with advanced cancer will experience significant pain at some point. In addition, 55\% of patients undergoing chemotherapy treatment and $66 \%$ of patients with advanced cancer, metastatic, or terminal disease experienced pain [6]. However, people still underestimated cancer pain. As a result, they do not adequately assess and treat cancer pain, associated with poor physical outcomes [7]. Cancer pain that is not treated adequately will affect the patient's quality of life, perform daily activities, and cause significant psychological distress [8].

Several attempts have been made to establish effective cancer pain management. Opioid analgesics are often used to treat cancer pain. Based on the World Health Organization and National Comprehensive Cancer Network pain management guidelines, the use of opioid analgesics is intended for moderate and severe pain [9,10]. Cancer patients with moderate to severe and persistent pain will be prescribed a long-acting opioid analgesic with an around-the-clock (ATC) dosing schedule; that is, the analgesic dose should be given at appropriate fixed time intervals. This strategy can consistently relieve pain [10-12]. The key to the effectiveness of the ATC dosage is adherence to the medication on a predefined schedule. Nevertheless, unfortunately, adherence to pain medication still lacks, so pain management is ineffective [13].

Educational interventions are needed to increase patient knowledge that can positively impact patient adherence to their therapy. That will increase the success of cancer pain therapy, especially in outpatients who will consume opioid analgesics without being accompanied by medical personnel. The authors choose a digital booklet to compare its effectiveness with counseling because of the current development of the digital era, making it easier for everyone to access information digitally. Through a digital booklet, it is easy for patients to find information about the opioid analgesics they used. This study aimed to compare the effectiveness of counseling and digital booklet on the level of adherence and pain scale at Dharmais Cancer Hospital from March to April 2021.

\section{METHODS}

This study used a quasi-experimental design with a non-equivalent control group. Therefore, the grouping of sample members in the counseling group and digital booklet group is not random. The population in this study was all outpatient cancer patients who received opioid analgesics at Dharmais Cancer Hospital. Samples were determined by consecutive sampling method with inclusion and exclusion criteria as follows:

\section{Inclusion criteria}

The following criteria were included in the study:

a. Patients $>18$ years old

b. The patient can read

c. Outpatients diagnosed by doctors at Dharmais Cancer Hospital who have cancer 
d. Patients receiving opioid analgesics at doses around the clock have used the same drug in the previous 2 weeks or more

e. Patients are willing to be research respondents.

\section{Exclusion criteria}

The following criteria were excluded from the study:

a. Patients underwent surgery in the past 3 days

b. Patients experience other pain except for cancer pain

c. Patients experience mental disorders and disorientation

d. Lost follow-up.

The research sample consisting of 134 people was divided into Group A (counseling group, $\mathrm{n}=67$ ) and Group $\mathrm{B}$ (digital booklet group, $\mathrm{n}=67$ ). Group A received counseling by the pharmacist, which included: Explanation of cancer pain, cancer pain treatment, opioid analgesics used by the patient, dosage, frequency of drug use, timing of drug use, how to use drugs, side effects, contraindications, drug interactions, storage and disposal of drugs, goals of treatment, and the importance of adherence to therapy. Counseling is given after the respondent completed the pre-test. Counseling is carried out for 15-20 min in the counseling room of the Dharmais Cancer Hospital. Meanwhile, Group B received validated digital booklets after the respondent completed the pre-test. The digital booklet file in pdf format is sent through WhatsApp Messenger from the researcher to the patient/patient's family.

In this study, pre-test and post-test were carried out using Morisky Medication Adherence Scale (MMAS-8) and pill count method to measure adherence and Numerical Rating Scale to measure pain scale. First, Group A and GROUP B are measured their adherence level and baseline pain scale, respectively. Then, the intervention was given on the $1^{\text {st }}$ day. Finally, the adherence level and pain scale were measured 2 weeks after the intervention. Descriptive statistics, Chi-square test, Wilcoxon test, Mann-Whitney test, Marginal Homogeneity test, and Spearman correlation were used in data analysis.

\section{RESULTS}

Respondents were dominated by 83 females (62\%), 86 people (64\%) aged 41-60 years, and 54 people (40\%) who graduated from high school, and as many as 84 people $(62 \%)$ who did not work. The number of respondents with moderate and low levels of adherence at the beginning of the study was 65 people $(49 \%)$, and the medium value of pain scale was 8 . The statistical analysis results showed no significant difference $(p>0.05)$ between each variable in the counseling and the digital booklet group. Complete data are shown in Table 1 .

In the counseling group and digital booklet, the respondents experienced an increase in adherence after being given the intervention. The result of statistical analysis using the Marginal Homogeneity test obtained $p=0.000$. This result indicates a significant difference in adherence before and after the intervention, so the conclusion is that providing each counseling and digital booklet can increase the adherence of cancer pain patients to their therapy using opioid analgesics. Changes in the level of adherence are shown in Figs. 1 and 2.

A decrease is shown in the average pain scale in the counseling group and digital booklet after each group was given intervention. The mean pain scale before and after the provision of counseling was $7.82 \pm 1.205$ and $6.88 \pm 1.376(p=0.000)$, respectively. Meanwhile, the mean pain scale before and after the provision of the digital booklet was $7.52 \pm 1.050$ and $6.81 \pm 1.171(\mathrm{p}=0.000)$, respectively. Based on analysis using the Wilcoxon test, there is a significant difference in the mean pain scale before and after the intervention $(p<0.05)$; hence, the conclusion is that each counseling and digital booklet can decrease the pain scale (Table 2).

The Mann-Whitney test results on changes in adherence using MMAS-8 obtained $p=0.005$. This result shows a significant difference between the effects of counseling and digital booklet on increasing respondent
Table 1: Characteristics of respondents

\begin{tabular}{|c|c|c|c|}
\hline \multirow[t]{2}{*}{ Characteristic } & \multicolumn{2}{|c|}{ Frequency (n \%) } & \multirow[t]{2}{*}{ p-value } \\
\hline & $\begin{array}{l}\text { Counseling } \\
(n=67)\end{array}$ & $\begin{array}{l}\text { Digital Booklet } \\
(n=67)\end{array}$ & \\
\hline \multicolumn{4}{|l|}{ Gender } \\
\hline Male & $27(40.3)$ & $24(35.8)$ & \multirow[t]{2}{*}{0.722} \\
\hline Female & $40(59.7)$ & $43(64.2)$ & \\
\hline \multicolumn{4}{|l|}{ Age } \\
\hline 19-40 years old & $9(13.4)$ & $16(23.9)$ & \multirow[t]{3}{*}{0.109} \\
\hline $41-60$ years old & $43(64.2)$ & $43(64.2)$ & \\
\hline$>60$ years old & $15(22.4)$ & $8(11.9)$ & \\
\hline \multicolumn{4}{|l|}{ Education } \\
\hline Elementary School & $19(26.3)$ & $8(11.9)$ & \multirow[t]{4}{*}{0.109} \\
\hline Junior High School & $12(17.9)$ & $11(16.4)$ & \\
\hline Senior High School & $21(31.3)$ & $33(49.3)$ & \\
\hline University & $15(22.4)$ & $15(22.4)$ & \\
\hline \multicolumn{4}{|l|}{ Working status } \\
\hline Working & $25(37.3)$ & $25(37.3)$ & \multirow[t]{2}{*}{1.00} \\
\hline Not working & $42(62.7)$ & $42(62.7)$ & \\
\hline \multicolumn{4}{|l|}{$\begin{array}{l}\text { Amount of medicine } \\
\text { prescribed }\end{array}$} \\
\hline One medicine & $24(35.8)$ & $24(35.8)$ & \multirow{3}{*}{0.973} \\
\hline Two medicines & $13(19.4)$ & $14(20.9)$ & \\
\hline More than two medicines & $30(44.8)$ & $29(43.9)$ & \\
\hline \multicolumn{4}{|c|}{ Adverse effect } \\
\hline Experienced & $21(31.3)$ & $22(32.8)$ & \multirow[t]{2}{*}{1.00} \\
\hline Not experienced & $46(68.7)$ & $45(67.2)$ & \\
\hline \multicolumn{4}{|l|}{ How to use medicine } \\
\hline Right & $67(100)$ & $65(97.0)$ & \multirow[t]{2}{*}{0.496} \\
\hline Not right & $0(0)$ & $2(3.0)$ & \\
\hline \multicolumn{4}{|l|}{ Using other medicine } \\
\hline Yes & $11(16.4)$ & $9(13.4)$ & \multirow[t]{2}{*}{0.809} \\
\hline No & $56(83.6)$ & $58(86.6)$ & \\
\hline \multicolumn{4}{|l|}{$\begin{array}{l}\text { Using of non-opioid } \\
\text { analgesics }\end{array}$} \\
\hline Yes & $13(19.4)$ & $12(17.9)$ & \multirow[t]{2}{*}{1.00} \\
\hline No & $54(80.6)$ & $55(82.1)$ & \\
\hline Using of adjuvants & & & \\
\hline Yes & $13(19.4)$ & $15(22.4)$ & 0.832 \\
\hline No & $54(80.6)$ & $52(77.6)$ & \\
\hline Type of Cancer & & & \\
\hline Breast cancer & $32(47.8)$ & $18(26.9)$ & 0.139 \\
\hline Prostate cancer & $9(13.4)$ & $9(13.4)$ & \\
\hline Head and neck cancer & $6(9.0)$ & $9(13.4)$ & \\
\hline Colorectal cancer & $4(6.0)$ & $7(10.4)$ & \\
\hline Other cancer & $16(23.9)$ & $24(35.8)$ & \\
\hline Stage of cancer & & & \\
\hline Stage I & $1(1.5)$ & $1(1.5)$ & 0.075 \\
\hline Stage II & $19(28.4)$ & $7(10.4)$ & \\
\hline Stage III & $19(28.4)$ & $23(34.3)$ & \\
\hline Stage IV & $28(41.8)$ & $36(53.7)$ & \\
\hline Level of adherence & & & \\
\hline High & $18(26.9)$ & $14(20.9)$ & 0.080 \\
\hline Moderate & $48(71.6)$ & $46(68.7)$ & \\
\hline Low & $1(1.5)$ & $7(10.4)$ & \\
\hline $\begin{array}{l}\text { Pain scale (Median, Min- } \\
\text { Max) }\end{array}$ & $8(5-10)$ & $8(5-10)$ & 0.167 \\
\hline
\end{tabular}

compliance. However, the results of the Mann-Whitney test on changes in the average pain scale obtained $p=0.132$, indicating that there is no significant difference between the effects of counseling and digital booklet on reducing the pain scale of the respondents. Details are shown in Table 3

Multivariate analysis with binary logistic regression was performed on confounding variables with a value $p<0.25$ using the Chi-square test. The results showed that age had a significant effect on increasing adherence $(p=0.017)$. Meanwhile, the education level $(p=0.838)$ did not significantly affect the increase in adherence. The pain scale was not significantly affected by the cancer stage $(p=0.081)$. 


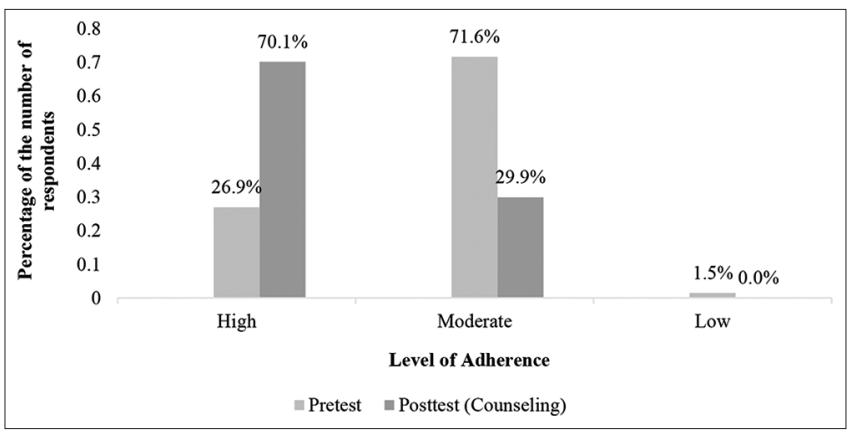

Fig. 1: Changes in the level of adherence after intervention (counseling)

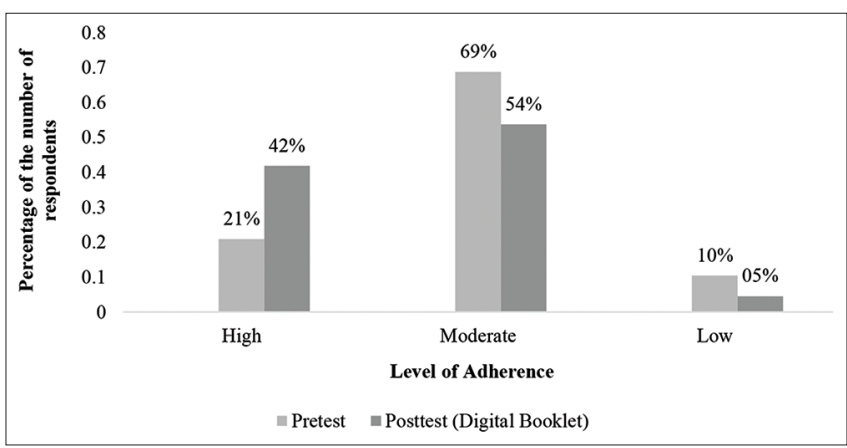

Fig. 2: Changes in the level of adherence after intervention (digital booklet)

Table 2: Changes in average pain scale after intervention

\begin{tabular}{|c|c|c|c|c|c|}
\hline \multirow[t]{3}{*}{ Group } & \multicolumn{4}{|l|}{ Pain Scale } & \multirow[t]{3}{*}{ p-value } \\
\hline & \multicolumn{2}{|l|}{ Pre-test } & \multicolumn{2}{|l|}{ Post-test } & \\
\hline & Mean $\pm \mathrm{SD}^{+}$ & $\begin{array}{l}\text { Median } \\
\text { (Min- } \\
\text { Max) }\end{array}$ & Mean $\pm S^{+}$ & $\begin{array}{l}\text { Median } \\
\text { (Min- } \\
\text { Max) }\end{array}$ & \\
\hline Counseling & $7.82 \pm 1.205$ & $8(5-10)$ & $6.88 \pm 1.376$ & $7(3-9)$ & $0.000^{*}$ \\
\hline $\begin{array}{l}\text { Digital } \\
\text { booklet }\end{array}$ & $7.52 \pm 1.050$ & $8(5-10)$ & $6.81 \pm 1.171$ & 7 (4-9) & $0.000^{*}$ \\
\hline
\end{tabular}

${ }^{*}$ There is a significant difference at $\mathrm{p}<0.05,+$ SD: Standard deviation.

Table 3: Changes in adherence score and pain scale after intervention

\begin{tabular}{llll}
\hline Group & \multicolumn{2}{l}{$\begin{array}{l}\text { Changes after intervention } \\
\text { (Mean } \pm \text { SD+) }\end{array}$} & $\begin{array}{l}\text { Median } \\
\text { (Min-Max) }\end{array}$ \\
\cline { 2 - 3 } & Counseling & Digital Booklet & \\
\hline Adherence Score & $1.04 \pm 0.824$ & $0.66 \pm 0.789$ & $0.005^{*}$ \\
Pain Scale & $0.94 \pm 1.113$ & $0.72 \pm 1.139$ & 0.132 \\
\hline
\end{tabular}

*There is a significant difference at $\mathrm{p}<0.05,+\mathrm{SD}$ : Standard deviation.

\section{DISCUSSION}

Most respondents who received opioid analgesics were cancer Stages III and IV. Pain is widespread in advanced cancer, affecting more than $60 \%$ of patients with an advanced, metastatic, or terminal disease. However, cancer pain is also experienced in the early stages of the disease. About a third of patients have undergone curative treatment experience pain. Several types of cancer are associated explicitly with a high prevalence of pain in the early stages of the disease, including pancreatic cancer and head and neck cancer [14]. The intensity of pain is not always related to cancer growth. A small tumor pressing on a nerve can be very painful, while a large tumor elsewhere may not cause pain [15].
Various studies have shown that providing education to cancer patients can improve adherence to opioid analgesic treatment [16-18]. In addition, patient knowledge about opioid use and medication adherence $(p=0.021)$ improved after the clinical pharmacist provided information. The relationship between patients' beliefs about opioids and their adherence to pain medication was analyzed by Liang et al. [19]. In that research, Liang et al. revealed that negative opinions about opioids led to poorer adherence to analgesic treatment. However, in the study of Savas et al., patient adherence levels before and after intervention were compared and categorized as increasing, decreasing, and constant. In that study, it was shown that an increased belief about the need for medication was associated with a positive adherence score [20]. Cancer patients generally go to the hospital accompanied by family or relatives, who may affect the patient's perception of pain control and pain medication. Therefore, patient companions need to be involved in every educational intervention to achieve better pain management.

Based on analysis using the Wilcoxon test, there is a significant difference in the mean pain scale before and after the intervention $(\mathrm{p}<0.05)$; hence, it can be concluded that each counseling and digital booklet can decrease the pain scale. The results of this study are in line with research conducted in Korea regarding the provision of education to cancer pain patients receiving opioid analgesics. In that study, there was a significant reduction in overall pain intensity after the intervention. In addition, severe cancer pain was significantly reduced in inpatient and outpatients, and more significant pain changes were seen in outpatients [21].

The same research results were also expressed by Yildirim et al. [22]. At weeks 2,4 , and 8, patients in the intervention group who were given a pain education booklet experienced a statistically significant reduction in pain intensity $(\mathrm{p}<0.05)$, while patients in the control group did not experience a significant decrease in pain intensity [22].

Although currently available pharmacological or non-pharmacological approaches to the management of cancer pain, they are mainly ineffective. This ineffectiveness may be related to several obstacles. One of the most common barriers is a lack of knowledge and negative attitudes toward cancer pain management [23]. This barrier can be remedied by providing counseling to help patients understand opioid therapy regarding its benefits or side effects. However, recent studies have shown that pain education alone cannot control pain well. Therefore, it needs to be accompanied by counseling on pain control strategies, such as pharmacological and non-pharmacological approaches, knowledge of pharmacological treatment, pain assessment, pain evaluation, and pain communication [24].

The advantage of counseling is that pharmacists can get more information from patients regarding diseases and drugs that are being used. Pharmacists can also provide patients with the empathy and support they need to stay enthusiastic about therapy. Digital booklets are also practical and easily accessible media that can be given to patients to access information at any time regarding the opioid analgesics they are using.

Several studies $[16,17,25,26]$ also proved a significant reduction in pain scale after education by clinical pharmacists. Patient characteristics and external factors need to be considered because they may influence pain control $[22,25,27]$.

The Chi-square test results on changes in the level of adherence showed a significant difference between the effects of counseling and digital booklet on increasing respondent compliance. However, the results of the Mann-Whitney test on changes in the average pain scale showed no significant difference between the effects of counseling and digital booklet on reducing the pain scale of the respondents. The difference in the effect of the two interventions becomes insignificant, possibly due to the small number of samples, the short study time, and the small changes in the mean pain scale. Apart from that, cancer pain is 
also objective in nature. In terms of measurement, there may be bias because the patient self-reports the pain they feel. According to the American Cancer Society, the pain intensity felt by patients also depends on various factors, including the type of cancer, the stage of cancer, and the patient's tolerance for pain. Patients with advanced cancer are more likely to experience pain [28]. In this study, factors affecting pain other than cancer were avoided in the exclusion criteria. The respondent did not experience any other illness that caused pain, and the respondent did not undergo surgery in the last 3 days.

Although the change in pain scale between the counseling group and the digital booklet was not statistically significant, the reduction in the pain scale in the counseling group was more significant than the decrease in the pain scale in the digital booklet group. Thus, overall, adherent increasing and pain scale reduction by counseling is better than a digital booklet.

According to Savas et al., patient beliefs, concerns, and misconceptions about opioid analgesics are significant components of cancer pain management along with appropriate analgesic treatment. Therefore, the involvement of a clinical pharmacist in the pain management team can minimize patient misunderstandings, increase patient knowledge, and improve medication adherence. All these aspects are expected to help achieve better pain control and improve the quality of life for patients [20].

The relationship between changes in the level of adherence as seen from the MMAS- 8 and pill count scores with the intensity of the pain scale was tested using Spearman correlation. The test results showed a positive correlation with low relationship strength $(\mathrm{r}=0.084)$. Thus, the higher the level of adherence, the lower the pain scale experienced by the patients. However, this relationship was not statistically significant $(\mathrm{p}>0.05)$.

This study has several limitations. First, this research design does not apply control variables. This design can limit the effectiveness of individual educational interventions as well as the generalizability of research findings. Second, this study cannot determine how long the effectiveness of education will last for pain control, so it cannot ensure the right time for the following education provision. Education is only given once. Therefore, further research is needed to investigate the longterm effects of interventions that can contribute to more effective pain management. Third, the small sample size and short study duration do not adequately reflect the effect of adherence to cancer pain control. It can also cause the factors that affect the level of adherence and pain scale in cancer patients not delineated.

\section{CONCLUSIONS}

Provision of counseling by pharmacists can improve adherence $(p<0.05)$ and decrease pain scale $(p<0.05)$ in cancer pain patients using opioid analgesics. Furthermore, providing the digital booklet to cancer patients using opioid analgesics can improve adherence $(p<0.05)$ and decrease the pain scale $(\mathrm{p}<0.05)$. Nevertheless, the provision of counseling by pharmacists is better than a digital booklet in increasing adherence level and decreasing pain scale in cancer pain patients at Dharmais Cancer Hospital. Further research with a more significant number of respondents could better represent the cancer pain patient population. Research covering a more extended period is also required. In addition, further research comparing a control group with an intervention group is required.

\section{ACKNOWLEDGMENT}

The authors thank Dharmais Cancer Hospital for allowing and facilitating authors in data collection and intervention to patients.

\section{AUTHOR'S CONTRIBUTIONS}

Rurynta Ferly Shavira and Risani Andalasia Putri discussed the study conception and design in consultation with Retnosari Andrajati.
Rurynta Ferly Shavira performed an intervention, data collection, and analysis. All authors discussed the final manuscript.

\section{CONFLICTS OF INTERESTS}

All authors stated no potential conflict of interest with research, authorship, and publication of this article.

\section{AUTHORS' FUNDING}

Any grant sources did not fund this research.

\section{REFERENCES}

1. GLOBOCAN. International agency for research on cancer 2020. Global Cancer Observatory Cancer Today 2020;419:1-2.

2. Vos T, Abajobir AA, Abbafati C, Abbas KM, Abate KH, Abd-Allah F, et al. Global, regional, and national incidence, prevalence, and years lived with disability for 328 diseases and injuries for 195 countries. A systematic analysis for the global burden of disease study 2016. Lancet 2017;390:1211-59.

3. van Leeuwen M, Husson O, Alberti P, Arraras JI, Chinot OL, Costantini A, et al. Understanding the quality of life ( $Q O L)$ issues in survivors of cancer: Towards the development of an EORTC QOL cancer survivorship questionnaire. Health Qual Life Outcomes 2018;16:1-15.

4. Damodar G, Gopinath S, Vijayakumar S, Rao A. Reasons for low quality of life in south Indian cancer patient population: A prospective observational study. Indian J Pharm Sci 2014;76:2-9.

5. Hui D, Bruera E. A personalized approach to assessing and managing pain in patients with cancer. J Clin Oncol 2014;32:1640-6.

6. Van Den Beuken MH, Hochstenbach LM, Joosten EA, Tjan-Heijnen VC, Janssen DJ. Update on prevalence of pain in patients with cancer: Systematic review and meta-analysis. J Pain Symptom Manage 2015;51:1070-90.

7. Bevilacqua LA, Dulak D, Schofield E, Starr TD, Nelson CJ, Roth AJ, et al. Prevalence and predictors of depression, pain, and fatigue in olderversus younger-adult cancer survivors. Psychooncology 2020;27:900-7.

8. Lau J, Flamer D, Murphy-Kane P. Interventional anesthesia and palliative care collaboration to manage cancer pain: A narrative review. Can J Anesth 2020;67:235-46.

9. Swarm RA, Paice JA, Anghelescu DL, Are M, Bruce JY, Buga S, et al. Adult cancer pain version 3. J Natl Comprehensive Cancer Network 2019;7:977-1007.

10. World Health Organization. WHO Guidelines for the Pharmacological and Radiotherapeutic Management of Cancer Pain in Adults and Adolescents. Geneva: World Health Organization; 2018.

11. Portenoy RK, Ahmed E. Principles of opioid use in cancer pain. J Clin Oncol 2014;32:1662-70.

12. Bruera E, Paice JA. Cancer pain management: Safe and effective use of opioids. Am Soc Clin Oncol Educ Book 2015;35:e593-9.

13. Yeager D, Williams K, Bai J, Cooper H, Quest T, Meghani S, Bruner DW. Factors related to adherence to opioids in black patients with cancer pain. J Pain Symptom Manage 2019;57:28-36.

14. Fallon M, Giusti R, Aielli F, Hoskin P, Rolke R, Sharma M, et al. Management of cancer pain in adult patients: ESMO clinical practice guidelines. Ann Oncol 2018;29:166-91.

15. ESMO. ESMO Patient Guide Series. Lugano, Switzerland: ESMO; 2018. p. 1-55.

16. Jahn P, Kuss O, Schmidt H, Bauer A, Kitzmantel M, Jordan K, et al. Improvement of pain-related self-management for cancer patients through a modular transitional nursing intervention: A clusterrandomized multicenter trial. Pain 2014;155:746-54.

17. Lin CC, Chou PL, Wu SL, Chang YC, Lai YL. Long-term effectiveness of a patient and family pain education program on overcoming barriers to management of cancer pain. Pain 2006;122:271-81.

18. Ramesh A, Rajanandh MG, Thanmayee S, Merin GS, Suresh S, Srinivas KS. Impact of patient counseling on medication adherence, beliefs and satisfaction about oral chemotherapies in patients with metastatic cancer at a super specialty hospital. Int J Cancer Res 2015;11:128-35

19. Liang SY, Chen KP, Tsay SL, Wu SF, Chuang YH, Wang TJ, et al. Relationship between belief about analgesics, analgesic adherence and pain experience in taiwanese cancer outpatients. Asian Pac J Cancer Prev 2013;14:713-6.

20. Savas M, Bayraktar-Ekincioglu A, Celebi N. An evaluation of cancer patients' opinions about use of opioid analgesics and the role of 
clinical pharmacist in patient education in Turkey. Int J Clin Pharm 2020;43:375-82

21. Koh SJ, Keam B, Hyun MK, Seo JJ, Park KU, Oh SY, et al. Cancer pain management education rectifies patients' misconceptions of cancer pain, reduces pain, and improves quality of life. Pain Med 2018;19:2546-55.

22. Yildirim YK, Cicek F, Uyar M. Effects of pain education program on pain intensity, pain treatment satisfaction, and barriers in Turkish cancer patients. Pain Manage Nurs 2009;10:220-8.

23. Makhlouf SM, Pini S, Ahmed S, Bennett MI. Managing pain in people with cancer-a systematic review of the attitudes and knowledge of professionals, patients, caregivers and public. J Cancer Educ 2020;35:214-40.

24. Oldenmenger WH, Sillevis Smitt PA, Van Montfort CA, De Raaf PJ, Van Der Rijt CC. A combined pain consultation and pain education program decreases average and current pain and decreases interference in daily life by pain in oncology outpatients: A randomized controlled trial. Pain 2011;152:2632-9.

25. Syrjala KL, Abrams JR, Polissar NL, Hansberry J, Robison J, DuPen S, et al. Patient training in cancer pain management using integrated print and video materials: A multisite randomized controlled trial. Pain 2008;1-2:175-86.

26. Lovell MR, Forder PM, Stockler MR, Butow P, Briganti EM, Chye R, et al. A randomized controlled trial of a standardized educational intervention for patients with cancer pain. J Pain Symptom Manage 2010;40:49-59.

27. Thomas ML, Elliott JL, Rao SM, Fahey KF, Paul SM, Miaskowski C. A randomized, clinical trial of education or motivational-interviewingbased coaching compared to usual care to improve cancer pain management. Oncol Nurs Forum 2012;39:39-49.

28. American Cancer Society. Facts About Cancer Pain. Cancer Pain. United States: American Cancer Society; 2019. p. 1-5. 